Ambiente \& Água - An Interdisciplinary Journal of Applied Science
ISSN 1980-993X - doi:10.4136/1980-993X
www.ambi-agua.net
E-mail: ambi-agua@agro.unitau.br

\title{
Tratamento de lixiviados de aterros de resíduos sólidos utilizando Processos Fenton e Foto-Fenton Solar
}

\author{
doi: 10.4136/ambi-agua.1483 \\ Received: 12 Aug. 2014; Accepted: 15 Sep. 2014 \\ Fábio Moraes da Costa ${ }^{1}$; Juacyara Carbonelli Campos ${ }^{2 *}$; \\ Fabiana Valéria da Fonseca ${ }^{2}$; Daniele Maia Bila ${ }^{3}$ \\ ${ }^{1}$ Universidade Castelo Branco (UCB), Rio de Janeiro, RJ, Brasil \\ Programa de Pós-Graduação em Tecnologia de Processos Químicos e Bioquímicos da Escola de Química - UFRJ \\ ${ }^{2}$ Universidade Federal do Rio de Janeiro (UFRJ), Rio de Janeiro, RJ, Brasil \\ Departamento de Processos Inorgânicos \\ ${ }^{3}$ Universidade do Estado do Rio de Janeiro (UERJ), Rio de Janeiro, RJ, Brasil \\ Departamento de Engenharia Sanitária e do Meio Ambiente \\ "Autor correspondente: e-mail: juacyara@eq.ufrj.br, \\ fmcchemist@gmail.com, fabiana@eq.ufrj.br, danielebila@yahoo.com.br
}

\section{RESUMO}

O lixiviado de aterros de resíduos sólidos urbanos é uma complexa mistura de substâncias orgânicas e inorgânicas, que em sua composição causam danos ao meio ambiente, devido à elevada concentração de matéria orgânica recalcitrante e à toxicidade presente. A proposta deste trabalho envolve a aplicação dos processos oxidativos avançados (POA), como tratamento de lixiviado oriundos de dois aterros sanitários, Gericinó (Rio de Janeiro/RJ) e Gramacho (Duque de Caxias/RJ), dois aterros com mais de 30 anos de operação, sendo que o último encontra-se encerrado há 2 anos. O objetivo da utilização dos POA é melhorar a qualidade do lixiviado para um tratamento biológico subsequente, para isso foi utilizado o ensaio com a bactéria Aliivibrio fischeri para avaliação da toxicidade. Para o Processo Fenton-escuro, realizado em escala de bancada, nos experimentos realizados a $\mathrm{pH}=3,0$ e razão $\mathrm{Fe}^{+2}: \mathrm{H}_{2} \mathrm{O}_{2}$ igual a 1:5 foram obtidas remoções de $56 \%$ e $19 \%$ de DQO para os lixiviados oriundos de Gericinó e Gramacho, respectivamente. Para o Processo Foto-Fenton Solar, realizado em uma planta piloto, nos testes a $\mathrm{pH}=3,0$ e razão $\mathrm{Fe}^{+2}: \mathrm{H}_{2} \mathrm{O}_{2}$ igual a $1: 5$, foram alcançadas $88 \%$ e $78 \%$ de remoção de DQO. Essas condições permitiram uma diminuição da toxicidade dos lixiviados para valores de coeficiente de efeito igual a 50\% (CE 50\%) para Aliivibrio fischeri maior que 50\%, indicando um lixiviado mais adequado para tratamento biológico posterior.

Palavras-chave: Aliivibrio fischeri, aterro sanitário, processos oxidativos avançados, toxicidade.

\section{Treatment of landfill leachate using Fenton Processes and Photo.Fenton Solar}

\section{ABSTRACT}

The leachate from municipal solid waste landfills is a complex mixture of organic and inorganic substances, which can damage the environment due to toxicity 
and the high concentration of recalcitrant organic matter. This work applied advanced oxidation processes (AOP) to the treatment of leachate from the Gericinó (Rio de Janeiro / RJ) and Gramacho (Duque de Caxias / RJ) landfills. These landfills were both in operation for more than 30 years; the latter closed two years ago. The purpose of using AOP is to improve the leachate quality prior to a subsequent biological treatment. The bacteria Aliivibrio fischeri was used as a biological process for evaluation of toxicity. The Dark-Fenton Process employed in bench scale experiments with a $\mathrm{pH}$ of 3.0 and $\mathrm{Fe}^{+2}: \mathrm{H}_{2} \mathrm{O}_{2}$ ratio $=1: 5$ resulted in removals of $56 \%$ and $19 \%$ for COD leachate of the Gericinó and Gramacho leachates, respectively. The Solar Photo-Fenton Process conducted in pilot plant tests at $\mathrm{pH}=3.0$ and $\mathrm{Fe}^{+2}: \mathrm{H}_{2} \mathrm{O}_{2}$ ratio $=1: 5$ generated COD removal $88 \%$ and $78 \%$, respectively. These conditions led to a decrease in the toxicity of leachates' coefficient values to a degree equal to $50 \%$ - for Alivibrio fischeri greater than $50 \%$ - indicating a more suitable leachate for further biological treatment.

Keywords: Aliivibrio fischeri, advanced oxidation processes, landfill, toxicity.

\section{INTRODUÇÃO}

O tratamento para os lixiviados de aterros tem recebido significante atenção nos últimos anos, em especial as áreas municipais. Conforme Campos et al. (2013), os lixiviados apresentam elevadas concentrações de matéria orgânica recalcitrante (acima de $2000 \mathrm{mg} \mathrm{L}^{-1}$ de DQO e relação DBO/DQO menores que 0,05) e nitrogênio amoniacal (acima de $1000 \mathrm{mg} \mathrm{L}^{-1}$ ) e são tratados com a combinação de técnicas físico-químicos (coagulação/floculação) e biológicos, que segundo alguns autores (Campos et al., 2013; Gotvajn et al., 2009) os resultados apresentados não têm sido satisfatórios. Uma forma de tratamento que tem sido avaliada é o uso de Processos Oxidativos Avançados (POA) para pré-tratamento de lixiviado, para degradar quimicamente a matéria orgânica recalcitrante e aumentar a biodegradabilidade do lixiviado.

Os POA constituem um grupo de técnicas que envolvem a geração de espécies altamente oxidantes, de radicais hidroxila (Araujo et al., 2011). A aplicação dos POA geralmente visa à transformação oxidativa dos componentes, em substâncias biologicamente degradáveis, ou em substâncias mais facilmente elimináveis por processos físico-químicos convencionais, como as moléculas de corantes em efluentes têxteis (Kunz et al., 2002).

$\mathrm{O}$ radical hidroxila é um agente com elevado potencial de oxidação $\left(\mathrm{E}^{\mathrm{o}}=2,8 \mathrm{~V}\right)$, extremamente reativo e de pouca seletividade, que o torna capaz de atacar uma diversidade de moléculas orgânicas (Tell et al., 2001). A grande vantagem dos Processos Oxidativos Avançados reside no fato dela ser um tipo de tratamento destrutivo, ou seja, o contaminante não é simplesmente transferido de fase, mas sim degradado através de uma seqüência de reações químicas (Hassemer, 2006).

Entre os Processos Oxidativos Avançados, grande destaque tem sido dado ao uso do peróxido de hidrogênio em presença de sais de ferro, conhecido como o Processo Fenton, devido principalmente ao seu baixo custo e alta eficiência na degradação dos compostos recalcitrantes. O Processo Fenton consiste em um conjunto de reações cíclicas, que utilizam íons $\mathrm{Fe}^{+2}$ e $\mathrm{Fe}^{+3}$ como catalisadores, para decompor o peróxido de hidrogênio e produzir radicais hidroxila. $\mathrm{O}$ íon ferroso $\left(\mathrm{Fe}^{2+}\right)$ inicia e catalisa a decomposição do $\mathrm{H}_{2} \mathrm{O}_{2}$, resultando na geração de radicais hidroxila (Araujo et al., 2011), (Reação 1). A reação de íons férricos com peróxido de hidrogênio, conhecida como tipo-Fenton (Reação 2) permite a regeneração dos íons 
ferrosos, porém sua cinética é mais lenta. De acordo com Sun et al. (2007), as constantes de reação são $k_{1}=76,5 \mathrm{~L} \mathrm{~mol}^{-1} \mathrm{~s}^{-1}$ e $\mathrm{k}_{2}=0,01-0,02 \mathrm{~L} \mathrm{~mol}^{-1} \mathrm{~s}^{-1}$ para reações Fenton e Tipo-Fenton, respectivamente.

$$
\begin{aligned}
& \mathrm{Fe}^{+2}+\mathrm{H}_{2} \mathrm{O}_{2} \rightarrow \mathrm{Fe}^{+3}+\mathrm{H}^{-}+{ }^{\circ} \mathrm{OH}(\text { em meio ácido) } \\
& \mathrm{Fe}^{+3}+\mathrm{H}_{2} \mathrm{O}_{2} \rightarrow \mathrm{HO}_{2} \bullet+\mathrm{Fe}^{+2}+\mathrm{H}^{+}
\end{aligned}
$$

Além do Processo Fenton tradicional, que daqui por diante será denominado "Fenton-escuro", existe processos que utilizam a radiação ultravioleta, como os processos Foto-Fenton e Foto-Fenton solar (este último daqui por diante denominado "Fenton-solar"). No Fenton-solar, a luz solar atua como fonte de radiação que atua aumentando a regeneração do $\mathrm{Fe}^{+2}$ e a produção adicional de radicais hidroxilas (Reação 3). A utilização da radiação solar tem como principal objetivo a redução dos custos e aplicações em escala industrial. A maior eficiência deste POA em relação ao Fenton-escuro ocorre devido à regeneração do íon ferroso (Reação 4), dos quelatos orgânicos intermediários de $\mathrm{Fe}^{+3}$ e da fotólise direta do peróxido de hidrogênio, Reação (5) (Pignatello, 1992).

$$
\begin{aligned}
& \mathrm{Fe}^{+3}+\mathrm{H}_{2} \mathrm{O}+h v \longrightarrow \mathrm{Fe}^{+2}+\mathrm{H}^{+}+{ }^{\circ} \mathrm{OH} \\
& \mathrm{Fe}^{+3}\left(\mathrm{RCO}_{2}\right)^{+3}+h v \longrightarrow \mathrm{Fe}^{+2}+\mathrm{CO}_{2}+\mathrm{R}^{\cdot} \\
& \mathrm{H}_{2} \mathrm{O}_{2}+h v \longrightarrow 2{ }^{\circ} \mathrm{OH}
\end{aligned}
$$

A avaliação da ação dos POA no aumento da biodegradabilidade e na formação de intermediários tóxicos em efluentes líquidos pode ser realizada pela avaliação de testes de toxicidade utilizando bactérias, tais como a Aliivibrio fischeri. O princípio dos ensaios de toxicidade consiste em expor organismos-teste representativos no ambiente a várias concentrações de uma ou mais substâncias, durante determinado período de tempo, para avaliação de seu potencial tóxico, sendo os efeitos detectados através de respostas nos organismos (CETESB, 1990).

O presente estudo tem como objetivo avaliar o desempenho da aplicação dos Processos Fenton-escuro e Fenton-solar em lixiviados oriundos de dois aterros sanitários do Estado do Rio de Janeiro (Aterro Metropolitano de Gramacho e Aterro de Gericinó).

\section{MATERIAL E MÉTODOS}

\subsection{Breve descrição dos aterros geradores de lixiviados do presente estudo}

O Aterro Metropolitano de Gramacho situa-se em Duque de Caxias, município do Estado do Rio de Janeiro e ocupa uma área de $1,3 \mathrm{~km}^{2}$, margeando a Baía da Guanabara. Segundo Campos et al. (2013), o aterro operou de 1978 a 2012 e recebeu uma média de 9.500 ton dia $^{-1}$ de resíduos urbanos da Região Metropolitana do Rio de Janeiro. Ainda segundo os autores, no início da sua operação, a área era um lixão e recebia resíduos industriais; a partir de 1995, a área foi recuperada e desde então foi operado como aterro sanitário, recebendo apenas resíduos urbanos.

O Aterro Sanitário de Gericinó, no bairro de Bangu, RJ, foi constituído para as atividades de disposição de resíduos sólidos de origem residencial, comercial e resíduo de varrição pública e recebe em torno de 2.000 ton de resíduos diariamente e opera desde 1985. 
Ambos aterros são considerados antigos, pois possuem mais de 25 de operação, entretanto, o Aterro de Gramacho encontra-se desativado e o de Gericinó, ainda em operação.

As amostras de ambos lixiviados foram trazidas ao laboratório e mantidas sob refrigeração até o momento do processamento e análise.

\subsection{Processo Fenton-escuro}

Os experimentos do processo Fenton-escuro foram realizados em escala de bancada. Foram tratados $500 \mathrm{~mL}$ de amostra de lixiviado. A reação se iniciou com a adição de sulfato ferroso e $\mathrm{H}_{2} \mathrm{O}_{2}$. A concentração de peróxido de hidrogênio foi estabelecida com base na DQO inicial das amostras ( 1 de $\mathrm{H}_{2} \mathrm{O}_{2}$ para 1 de DQO) e a reação de decomposição do peróxido, considerando o oxigênio produzido equivale à demanda de oxigênio da amostra. A concentração de sulfato ferroso foi determinada de acordo com a dosagem de peróxido de hidrogênio, de forma a atender às razões mássicas $\mathrm{Fe}^{+2}: \mathrm{H}_{2} \mathrm{O}_{2}$ de 1:2, 1:5 e 1:10. Após adição de peróxido e sulfato ferroso o $\mathrm{pH}$ foi ajustado com adição de $\mathrm{H}_{2} \mathrm{SO}_{4}\left(1 \mathrm{~mol} \mathrm{~L}^{-1}\right)$ para os valores de 3 e 5 . Após 60 minutos, a reação foi interrompida com o ajuste de $\mathrm{pH}$ para 7,5 com adição de $\mathrm{NaOH}$ (50\%), ocorrendo assim a precipitação dos íons férricos. Os ensaios foram realizados com solução aquosa de sulfato ferroso heptahidratado P.A (Merck) e peróxido de hidrogênio 50\% v/v (Peróxidos do Brasil).

\subsection{Processo Foto-Fenton solar}

Os experimentos do processo Foto-Fenton solar foram realizados em uma unidade piloto acoplados a um reator solar de filme descendente, instalada na Universidade Federal do Rio de Janeiro (Figuras 1a e b). A composição da unidade piloto consiste em uma placa de polietileno com $1,37 \mathrm{~m}$ de comprimento por $0,82 \mathrm{~m}$ de largura e espessura de $0,01 \mathrm{~m}$. As tubulações são de meia polegada com 52 pontos de distribuição, calha receptora, bomba centrífuga modelo SHP - 35,05 V $(0,37 \mathrm{~kW})$, três tanques de tratamento: TQI (tanque alimentação, $20 \mathrm{~L}$ de capacidade), TQII (tanque de mistura com agitação mecânica, 20L), TQIII (tanque de armazenamento do efluente tratado, 50 litros de capacidade). A amostra de lixiviado foi colocada no TQ1 e com o auxílio de uma bomba centrifuga direcionada ao TQII, onde eram adicionados os reagentes. Após a passagem pela placa de polietileno (Figura 1b) e contato com o sol, a amostra era recirculada para o TQII. Ao final do tempo pré-estabelecido, coletava-se o lixiviado tratado no tanque TQIII.

A solução de $\mathrm{H}_{2} \mathrm{O}_{2}$ foi adicionada no TQII utilizando uma bomba peristáltica com vazão pré-determinada de forma a atender as concentrações desejadas. Após 60

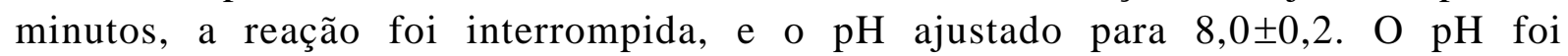
monitorado a cada minuto por medidor portátil Tecnopon, Modelo MPA 210P. A irradiação solar foi medida por um radiômetro KIMO, modelo SL100, durante toda a reação. As alíquotas do efluente tratado foram coletadas em 20, 40 e 60 minutos durante a reação.

Tal como no processo Fenton-escuro, a concentração de peróxido de hidrogênio foi estabelecida com base na DQO inicial das amostras, atendendo uma relação 1:1, da mesma maneira anterior. A concentração de sulfato ferroso foi determinada de acordo com a dosagem de peróxido de hidrogênio, de forma a atender as razões estudadas.

Todos os ensaios foram realizados em dias de sol e céu claro, e no horário de maior incidência de radiação, entre as $12 \mathrm{~h} 00$ e $14 \mathrm{~h} 00$, no período de agosto a outubro de 2013. A energia média acumulada foi medida em todos os experimentos de acordo com método baseado em Malato et al. (2002). 

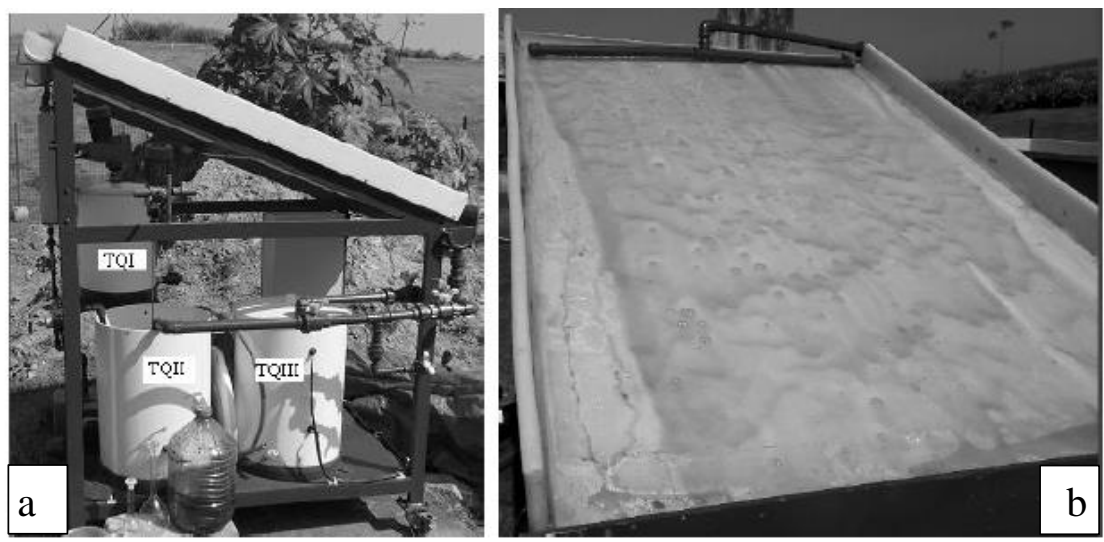

Figura 1. Unidade piloto solar. (a) detalhamento dos tanques (b) detalhamento do reator, tipo filme descendente.

Fonte: Freire (2012).

\subsection{Metodologia analítica}

\subsubsection{Análises físico-químicas}

A DQO foi determinada pelo método colorimétrico, descrito pela AWWA (APHA et al., 2005), refluxo fechado. Foi utilizado para a digestão das amostras o reator digital de DQO marca Hach, modelo DRB20025, e um espectrofotômetro marca Hach, modelo DR-2800 para a leitura da absorvância, após a etapa da digestão.

A concentração residual de peróxido de hidrogênio interfere na determinação da DQO, assim, é necessário quantificar o peróxido de hidrogênio residual e subtrair a contribuição de DQO relativa ao peróxido ao valor final de DQO. O peróxido de hidrogênio residual foi determinado de acordo com o procedimento baseado na reação entre o peróxido de hidrogênio e o íon metavanadato $\left(\mathrm{VO}^{-3}\right)$ (Oliveira et al., 2001).

\subsubsection{Toxicidade com Allivibrio fischeri}

O procedimento para a realização do ensaio foi realizado através Norma Técnica NBR 15411-3 (ABNT, 2012). Os resultados foram expressos em coeficiente de efeito a 50\% (CE 50\%). Os valores de CE50\% acima de 50\% foram considerados com baixa toxicidade para esse trabalho, seguindo recomendação de procedimento de TRIBEL (2002).

\section{RESULTADOS E DISCUSSÃO}

\subsection{Processo Fenton-Escuro}

Na Figura 2 são apresentados os resultados de DQO dos lixiviados dos aterros de Gericinó e Gramacho, respectivamente, após o tratamento com Processo Fenton-escuro. Para ambos os lixiviados, o pH igual a 3 produziu melhores resultados em 60 minutos de reação: as amostras do lixiviado de Gericinó tratadas por processo Fenton apresentaram eficiência de remoção de 49 a $56 \%$ enquanto para o lixiviado de Gramacho, foram obtidas remoções de 16 a $19 \%$ de DQO. A razão $\mathrm{Fe}^{+2}: \mathrm{H}_{2} \mathrm{O}_{2}$ igual a 1:5 foi a condição que gerou melhores resultados nestes experimentos para ambos os lixiviados

Sendo assim, em ambos lixiviados, o Fenton-escuro obteve melhor desempenho em pH igual 3 e razão $\mathrm{Fe}^{+2}: \mathrm{H}_{2} \mathrm{O}_{2}$ igual a 1:5, gerando resultados de eficiências de remoção de $56 \%$ e $19 \%$, respectivamente para os lixiviados de Gericinó e Gramacho. 
Campos et al. (2013) relataram que o lixiviado de Gramacho é de difícil tratabilidade devido à deposição de resíduos industriais no início de sua operação. Esse fato explica porque o Processo Fenton não foi tão efetivo para a sua redução de DQO, quanto foi para o outro lixiviado. Além disso, os mesmos autores destacam que o lixiviado de Gramacho apresenta elevadas concentrações de alcalinidade e cloreto, que podem agir interferindo na reação de Fenton, pois agem como "sequestrantes" de radicais hidroxila (Lin et al., 1999).

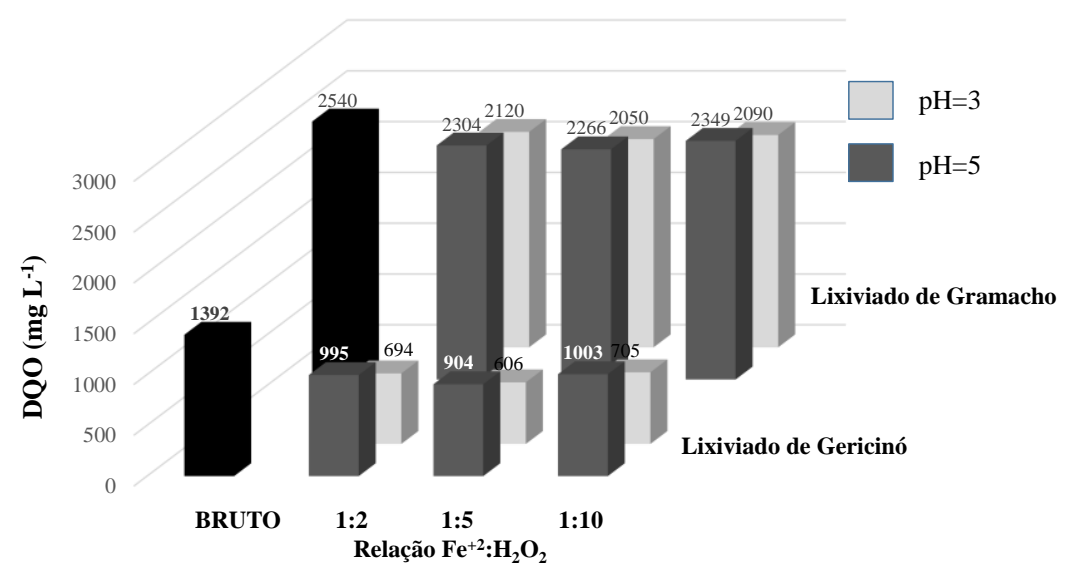

Figura 2. Resultados de DQO dos lixiviados de Gericinó e Gramacho bruto e tratados por processo Fenton -Escuro em diferentes razões $\mathrm{Fe}^{+2}: \mathrm{H}_{2} \mathrm{O}_{2}$. Condições: $\mathrm{H}_{2} \mathrm{O}_{2 \text { GERICINó }}=2958$ $\mathrm{mg} \mathrm{L}^{-1} ; \mathrm{H}_{2} \mathrm{O}_{2 \mathrm{GRAMACHO}}=5398 \mathrm{mg} \mathrm{L}^{-1}$ e tempo de reação= $60 \mathrm{~min}$.

O tempo de reação foi avaliado nessa condição que obteve os melhores resultados, como ilustrado na Figura 3.

Em até 20 minutos, a reação se realizou, não observando remoções adicionais significativas nos tempos posteriores. No processo Fenton, a queda inicial de DQO é mais rápida, em que tem-se uma maior disponibilidade dos íons $\mathrm{Fe}^{2+}$ para catalisar a decomposição do $\mathrm{H}_{2} \mathrm{O}_{2}$ em radicais hidroxilas (reação 1). Após um determinado período de reação, os íons ferrosos $\left(\mathrm{Fe}^{+2}\right)$ são oxidados a íons férricos $\left(\mathrm{Fe}^{+3}\right)$, formando complexos que podem levar a interrupção da reação de Fenton.

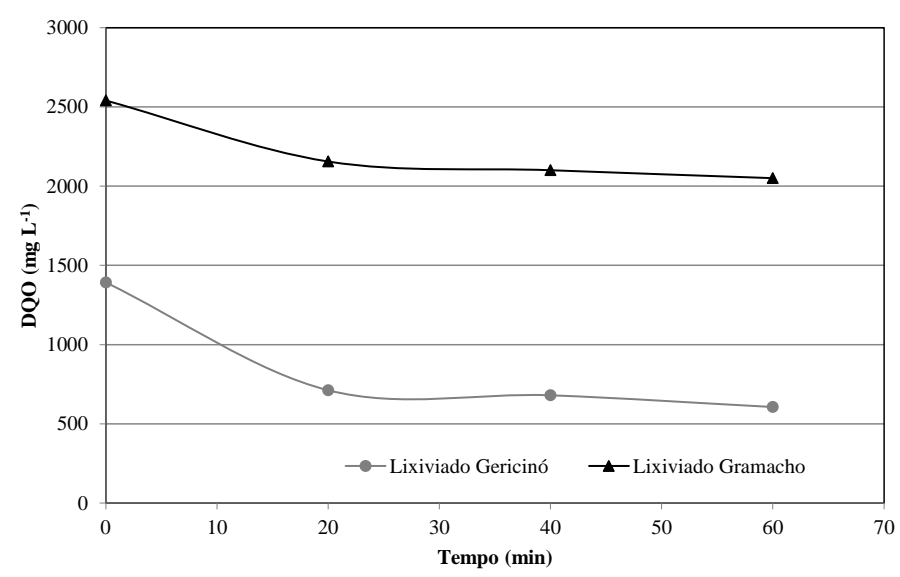

Figura 3. Resultados de DQO com o tempo de reação dos lixiviados de Gericinó e Gramacho tratados por processo Fenton-Escuro. Condições: pH 3,0, razão mássica Fe $\mathrm{Fe}_{2}^{+2} \mathrm{H}_{2} \mathrm{O}_{2}=1: 5 \mathrm{e} \mathrm{H}_{2} \mathrm{O}_{2 \text { GERICINÓ }}=2958 \mathrm{mg} \mathrm{L}^{-1} \mathrm{e}$ $\mathrm{H}_{2} \mathrm{O}_{2 \mathrm{GRAMACHO}}=5398 \mathrm{mg} \mathrm{L}^{-1}$. 


\subsection{Processo Fenton-Solar}

Na Figura 4 são apresentados os resultados de DQO dos lixiviados dos aterros de Gericinó e Gramacho, respectivamente, após o tratamento com o Processo Fenton-solar.

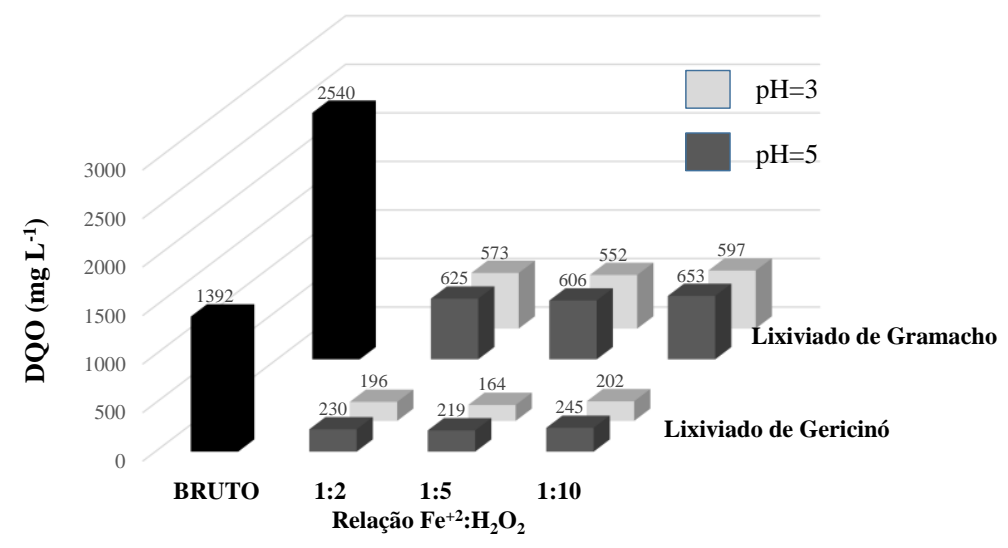

Figura 4. Resultados de DQO dos lixiviados de Gericinó e Gramachado bruto e tratados por processo Fenton-Solar em diferentes razões $\mathrm{Fe}^{+2}: \mathrm{H}_{2} \mathrm{O}_{2}$. Condições: $\quad \mathrm{H}_{2} \mathrm{O}_{2 \text { GERICINÓ }}=2958 \mathrm{mg} \mathrm{L}^{-1} \mathrm{e}$ $\mathrm{H}_{2} \mathrm{O}_{2 \mathrm{GRAMACHO}}=5398 \mathrm{mg} \mathrm{L}^{-1}$ e tempo de reação $=60 \mathrm{~min}$.

Como pode ser verificado, o processo Fenton-solar mostrou-se bastante efetivo na redução na DQO dos lixiviados estudados em diferentes condições experimentais. As mesmas condições que geraram os melhores desempenhos para o Fenton-escuro também foram as melhores para o Fenton-solar $\left(\mathrm{Fe}^{+2}: \mathrm{H}_{2} \mathrm{O}_{2}=1: 5 \mathrm{e} \mathrm{pH=3}\right)$. Nestas condições, os resultados de eficiência de remoção para a DQO foram de $88,2 \%$ e $78,2 \%$, respectivamente, para os lixiviados de Gericinó e Gramacho. Sendo assim, foi avaliado o tempo de reação nestas condições, conforme ilustrado na Figura 5.

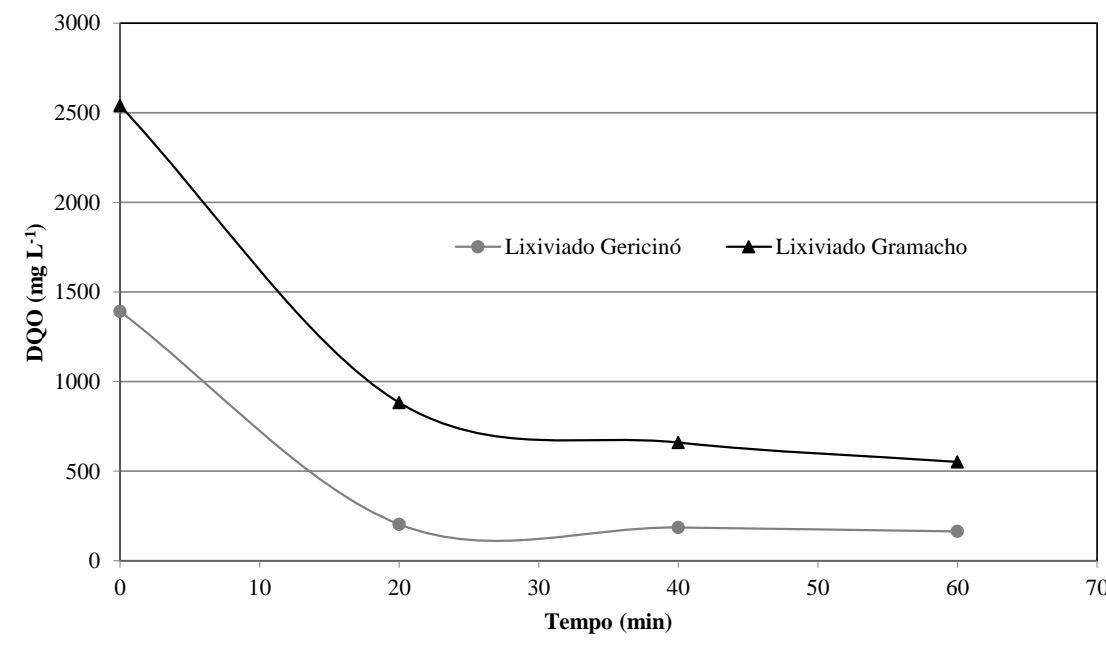

Figura 5. Resultados de DQO com o tempo de reação dos lixiviados de Gericinó e Gramacho tratados por processo Fenton-solar. Condições: $\mathrm{pH} 3,0$, razão mássica $\mathrm{Fe}^{+2}: \mathrm{H}_{2} \mathrm{O}_{2}=1: 5$ e $\mathrm{H}_{2} \mathrm{O}_{2 \text { GERICINÓ }}=2958 \mathrm{mg} \mathrm{L}^{-1}$ e $\mathrm{H}_{2} \mathrm{O}_{2 \text { GRAMACHO }}=5398 \mathrm{mg} \mathrm{L}^{-1}$. 
Da mesma maneira que o Fenton-escuro, houve a maior remoção de DQO nos primeiros 20 minutos de reação. A incidência da radiação UV sobre os complexos férricos favorece a regeneração de novos íons ferrosos, que continuam com o processo de decomposição do $\mathrm{H}_{2} \mathrm{O}_{2}$ (Araujo et al., 2011; Primo et al., 2008). A geração de mais radicais hidroxilas que oxidam a matéria orgânica, reação (3), favorecem a reação, enquanto que no processo Fenton-escuro ocorre a formação de substâncias estáveis complexadas pelos íons férricos, interrompendo rapidamente a reação. O que provavelmente levou a melhores resultados para a remoção da matéria orgânica nos dois lixiviados tratados no presente estudo pelo processo Fenton-solar. A energia média acumulada medida em todos os experimentos foi $643 \mathrm{~kJ} \mathrm{~L}^{-1}$.

\subsection{Avaliação de toxicidade com bactéria Allivibrio fischeri}

A Tabela 1 apresenta os resultados de toxicidade aguda com Allivibrio fischeri para as amostras brutas e tratadas por processo Fenton. Os valores indicam o percentual de cepas bioluminescentes remanescentes após contato com a amostra.

Verifica-se que o processo Fenton foi efetivo para diminuir a toxicidade do lixiviado às cepas bioluminescentes, o que pode indicar que um processo biológico de tratamento posterior seja possível. Comparando os dois lixiviados, o valor de toxicidade é maior para o lixiviado de Gramacho, tanto bruto quanto tratado por POA. Esses resultados são corroborados por Campos et al. (2013), que relataram a presença de DQO mais recalcitrante no lixiviado de Gramacho, o que dificulta a ação oxidativa do processo Fenton.

Tabela 1. Toxicidade CE $50 \%$ para as amostras do lixiviado de Gericinó e Gramacho. Condições: pH 3,0, razão mássica $\mathrm{Fe}^{+2}: \mathrm{H}_{2} \mathrm{O}_{2}=1: 5$ e $\mathrm{H}_{2} \mathrm{O}_{\text {2GERICINó }}=2958 \mathrm{mg} \mathrm{L}^{-1} \mathrm{e}$ $\mathrm{H}_{2} \mathrm{O}_{2 \mathrm{GRAMACHO}}=5398 \mathrm{mg} \mathrm{L}^{-1}$.

\begin{tabular}{lccc}
\hline & $\begin{array}{c}\text { Toxicidade CE 50\% } \\
\text { Amostra bruta (\%) }\end{array}$ & $\begin{array}{c}\text { Toxicidade CE 50\% } \\
\text { Fenton escuro (\%) }\end{array}$ & $\begin{array}{c}\text { Toxicidade CE 50\% } \\
\text { Fenton solar (\%) }\end{array}$ \\
\hline Lixiviado de Gericinó & 27 & 76 & 79 \\
Lixiviado de Gramacho & 13 & 54 & 59 \\
\hline
\end{tabular}

Ao contrário da DQO, não houve diferença de eficiência para os processos Fenton escuro e solar, para ambos lixiviados. No entanto, ambos processos só mostraram efeito de remoção de toxicidade no tempo de 60 minutos para os dois lixiviados. As alíquotas das amostras que foram retiradas em períodos intermediários, em 20 e 40 minutos, não demostraram eficiência no tratamento, mantendo a toxicidade dos compostos presentes nas amostras (resultados não apresentados).

\section{CONCLUSÕES}

Os resultados obtidos neste estudo revelaram que os processos Fenton e Foto Fenton solar são promissores no tratamento dos lixiviados dos aterros em estudo. Foi possível observar a redução da toxicidade com Allivibrio fischeri, o que indica que um tratamento biológico posterior seja aplicável e da DQO nas amostras de lixiviados tratadas dos aterros de Gericinó e Gramacho nas condições de pH igual a 3,0, razão mássica $\mathrm{Fe}^{+2}: \mathrm{H}_{2} \mathrm{O}_{2}=1: 5$ e 60 min de reação.

Embora os processos avaliados tenham apresentado boas eficiências de tratamento, comparativamente o processo Foto-Fenton se mostrou mais eficiente na remoção de DQO e toxicidade, indicando a importância da radiação UV solar na 
degradação da matéria orgânica recalcitrante e tóxica presente nos lixiviados estudados.

\section{AGRADECIMENTOS}

Apoio financeiro da FAPERJ (Fundação Carlos Chagas Filho de Amparo à Pesquisa do Estado do Rio de Janeiro) e CNPq (Conselho Nacional de Desenvolvimento Científico e Tecnológico). À Haztec Ambiental, unidade Belford Roxo, RJ, pela realização dos ensaios de toxicidade e à COMLURB (Companhia de Limpeza Urbana do Município do Rio de Janeiro) pelo envio de amostras de lixiviados.

\section{REFERÊNCIAS}

ASSOCIAÇÃO BRASILEIRA DE NORMAS TÉCNICAS - ABNT. NBR 15411-3. Determinação do efeito inibitório de amostras de água sobre a emissão de luz de Aliivibrio fischeri: método com utilização de bactérias liofilizadas. Rio de Janeiro, 2012.

AMERICAN PUBLIC HEALTH ASSOCIATION - APHA; AMERICAN WATER WORKS ASSOCIATION - AWWA; WATER ENVIRONMENT FEDERATION - WEF. Standard methods for the examination of water and wastewater. $21^{\text {th }}$ ed. Washington, DC, 2005.

ARAUJO, F. V. F.; YOKOYAMA, L.; TEIXEIRA, L. A. C.; CAMPOS, J. C. Heterogeneous fenton process using the mineral hematite for the discolouration of a reactive dye solution. Brazilian Journal of Chemical Engineering, v. 28, p. 605-616, 2011. http://dx.doi.org/10.1590/S0104-66322011000400006

CAMPOS, J. C.; MOURA, D.; COSTA, A. P.; YOKOYAMA, L.; ARAUJO, F. V. F.; CAMMAROTA, M. C. et al. Evaluation of $\mathrm{pH}$, alkalinity and temperature during air stripping process for ammonia removal from landfill leachate. Journal of Environmental Science and Health, Part A: Toxic/Hazardous Substances and Environmental Engineering, v. 48, n. 9, p. 1105-1113, 2013. http://dx.doi.org/10.1080/10934529.2013.774658

COMPANHIA DE TECNOLOGIA DE SANEAMENTO AMBIENTAL - CETESB. Procedimentos para utilização de testes de toxicidade no controle de efluentes líquidos. São Paulo, 1990. 17p.

FREIRE, L.F.A. Estudo do sistema Fenton-Solar aplicado a remoção de fenol, 2012. 94f. Dissertação (Mestrado em Tecnologia de Processos Químicos e Bioquímicos) - Escola de Química - UFRJ, Rio de Janeiro, 2012.

GOTVAJN, A. Z.; TISLER, T.; KONCAN, J. Z. Comparison of different treatment strategies for industrial landfill leachate. Journal of Hazardous Materials, v. 162, p. 1446 - 1456, 2009. http://dx.doi.org/10.1016/j.jhazmat.2008.06.037

HASSEMER, M. E. N. Oxidação fotoquímica - UV/ $\mathbf{H}_{2} \mathrm{O}_{2}$ - para degradação de poluentes em efluentes da indústria têxtil. 2006. 175f. Tese (Doutorado em Engenharia Ambiental) - UFSC, Florianópolis, 2006. 
KUNZ, A.; PERALTA-ZAMORA, P.; MORAES, S. G.; DURÁN, N. Novas tendências no tratamento de efluentes têxteis. Química Nova, v. 25, n. 1, p. 78 82, 2002. http://dx.doi.org/10.1590/S0100-40422002000100014

LIN, SHENG H.; LIN, C. M.; LEU, H. G. Operating characteristics and kinetics studies of surfactant wastewater treatment by Fenton oxidation. Water Research, v. 33, n. 7, p. 1735-1741, 1999. http://dx.doi.org/10.1016/S00431354(98)00403-5

MALATO, S.; BLANCO, J.; VIDAL, A.; RICHTER, C. Photocatalysis with solar energy at a pilot- plant scale: An overview. Applied Catalysis B: Environmental, v. 37, n. 1, p. 1-15, 2002. http://dx.doi.org/10.1016/S09263373(01)00315-0

OLIVEIRA, M. C.; NOGUEIRA, R. F. P.; GOMES NETO, J. A.; JARDIM, W. F.; ROHWEDDER, J. J. R. Sistema de injeção em fluxo espectrofotométrico para monitorar peróxido de hidrogênio residual em processo de fotodegradação por reação foto-Fenton. Química Nova, v. 24, n. 2, p. 188 - 190, 2001. http://dx.doi.org/10.1590/S0100-40422001000200007

PIGNATELlO, J. J. Dark and photoassisted $\mathrm{Fe}^{3+}$ - catalysed degradation of chlorophenoxy herbicides by hydrogen peroxide. Environmental Science \& Technology, v. 26, n. 5, p. 944-951, 1992. http://dx.doi.org/10.1021/es00029a012

PRIMO, O.; RIVERO, M. J.; ORTIZ, I. Photo-Fenton process as an efficient alternative to the treatment of landfill leachates. Journal of Hazardous Materials, v. 153, n. 1-2, p. 834-842, 2008. http://dx.doi.org/10.1016/j.jhazmat.2007.09.053

SUN, J. H.; SUN, S. P.; WANG, G. L.; QIAO, L-P. Degradation of azo dye amido black $10 \mathrm{~B}$ in aqueous solution by Fenton oxidation process. Dyes and Pigments, v.74, 647-652, 2007. http://dx.doi.org/10.1016/j.dyepig.2006.04.006

TELL, A. L.; WARBERG, C. R.; ATKINSON, D. A.; WATTS, R. J. Comparison of mineral and soluble iron Fenton catalysts for the treatment of trichloroetilene. Water Research, v. 35, n. 4, p. 977-984, 2001.

http://dx.doi.org/10.1016/S0043-1354(00)00332-8

TRATAMENTO DE RESÍDUOS INDUSTRIAIS DE BELFORD ROXO - TRIBEL. Procedimento TRLAB-MA-02. Determinação da toxicidade aguda de substâncias químicas e efluentes para bactérias marinhas Vibrio fischeri. Belford Roxo, 2002. 